\title{
Implementing Global Business Services in a Plural Sourcing Context: Conceptualizing Modes of Service Governance
}

\author{
Albert Plugge \\ Delft University of Technology \\ The Netherlands \\ a.g.plugge@ tudelft.nl
}

\begin{abstract}
To increase organizational responsiveness, firms nowadays seek various approaches in delivering global shared business services. Today, global operating firms apply a plural sourcing model that consists of both in-house and outsourced business services. As such, service governance is needed to manage interdependencies between vendors, both inhouse and outsourced. However, as far as we knowno study has yet addressed how global business services are governed within the context of plural sourcing. We conducted 68 semi-structured interviews with executive management of international firms and distributed a survey questionnaire to explore service governance modes. As a result, we identify five service governance modes: regional, global, centralized, de-centralized and multifunctional. Our paper contributes to research on global business services and plural sourcing by exploring various service governance modes. Theoretical and practical implications are discussed.
\end{abstract}

Keywords: Business Services, Plural Sourcing, Service Governance, Exploratory Research, Mini-Cases

\section{Introduction}

Due to the convergence of rapid business developments and challenges imposed by digitization of work processes, firm s nowadays a gain seek vario u s approaches in delivering global shared business services to achieve organizational responsiv e ness [1 2]. As such, shared services have become more popular as a service management option for globally operating firms when delivering business services [3-5]. The focus of this paper is not on business-to-end-user services (consumers or other businesses), but on business services that are used to support firms' internalbusiness processes; for example, Finance and Accounting (F\&A), Human Resources (HR), Su p ply Cha in Management (SCM), Information Technology (IT) or Procurement [6].

\author{
ShahrokhNikou \\ Åbo Aka demi University \& \\ Stockholm University \\ shahrokh.nikou@abo.fi
}

During the last decadefirms decided to bundle in house and outsourced business services and create flexibility to ca ter for changing internal circumstances. This approach resulted in a plural sourcing arrangement [7]. Today, plural sourcing is considered to be the modus operandi of firms [8]. Literature demonstrates multiple explanations for plural sourcing, ranging from safeguarding a gainst vendor opportunism [9] to complementarity of knowledge an d in centives [7]. In contrast to make-or-buy relationships, plural sourcing arrangements create an inherent coordination problem. Hence, service governance is needed to manage interdependencies between vendors (e.g., inhouse and outsourced).

As far as we know, no study, however, a ddressed how global business services are governed with in the context of plural sourcing. Aier et al. [10] argue that within the context of business services, service governance is still not well understood. The authors state that research in this field is required due to network externalities, involvement of business departments, and diversity of stakeholders, as the probability of inconsistent design and implementation of business services will increase.

Against the background of this call for more research, we suggest that service governance merit specific attention. This paperargues that firms may differ in how globalbusiness services are implemented and as such, require various service governance modes. The aim of this research is to explore how firm s deal with service governance of global business services within the context of plural sourcing. Based on the above discussion, following research question is formulated:

What type of service governancemodes are used by firms to implement global business services when applying a plural sourcing strategy?

Taking explicitly firm service governance ch oices into account, we answer the call of [11] for more explorative research in the context of business services. The authors argue that service sourcing and service outsourcing are examples of broad topics with firm relevance in need of scrutiny in marketing a nd business 
management ( $\mathrm{p}$ 2460). By investigating the service governance in the context of plural sourcing, we contribute to literature by highlighting that process excellence and a ligning firm s' operating model a re key rationales to implement global business services. Moreover, by identifying different service governance modes, we contribute to global business services, service governance and plural sourcing research.

This paper is organized as follows. Based on a litera ture background, first, we address the concepts of business services, plural sourcing, and service governance. By applying grounded theory as a theoretical lens, we introduce the research methodology, data collection and data analysis in Section 3. Next, we present ourfindings in Section 4. In addition, based on the identified service governance modes, we provide an embedded case studies to elaborate on the findings. Discussions and the conclusion are presented in Section 5 and 6, respectively.

\section{Literature review \\ 2.1. Business services}

Previous studies show thata firm's service strategy is influenced by the availability and need for their business services [11]. As argued by Wirtz et al. [5] business services consist of a variety of services (e.g., legal, accountancy, research and development, information technology). To improve effectiveness, organizations decompose their enterprise and corresponding business services into smaller autonomous business components. As such, bu siness services can be integrated and, or disintegrated to crea te enterprise ecosystem flexibility. Global Business Services (GBS) has been applied to a variety of models attempting to coordinate service delivery across multiple functions [1]. According to [12], GBS can be defined as an "integrated compilation of service offerings for any (multiple) support functions within a company $[. .$.$] globalin na ture and with respect to both$ delivery centers and customers". As a result, GBS models are different from the traditional a p proach of shared services and the past wave of outsourcing /offshoring and seeks to leverage the capabilities of vendors [1314].

Market research shows that GBS models can be characterized by their 'multi-nature' [1], namely: multi-function, multi-region, multi-business, and multisourcing a pproach. Applying a multi-sourcing strategy fits with the concept of plural sourcing. To implement a plural sourcing strategy, both a firm and its vendors have to focus on collaboration a s they have to work together intensively to exchange business service information. However, literature shows that colla boration within a plural-sourcing context is of ten problematic, because it is difficult to establish and monitor control and coordination mechanisms [15].

\subsection{Plural sourcing}

Plural sourcing research shows various definitions that address the combination of make, buy, and ally in a systematic way $[7,16]$. We build on the definitions of [17] and [18] and define plural sourcing as "the degree of simultaneous insourcing and outsourcing (make-and-buy) the same business service activities by a firm but differ from each other in their particular capabilities and limitations". Importantly, [18] a rgue that the boundaries of 'same' are inconsistently defined across and even within papers. We follow the a u tho rs reconceptualization of 'same' a a spectrum of degrees of 'similarity' and propose to study plural sourcing tasks that are complementary in nature.

The intuitively appealing a ssumption in the plu ral sourcing literature is that this concept ameliorates the weaknesses of insourcing and outsourcing [19]. Or in other words, plural sourcing creates best of both worlds when providing GBS. Interdependencies between in hou se and outsourced business services may influence the criticality of GBS and as such, the degree in which a business service is viewed as a critical enabler of business success [20]. Interdependencies incre a se the degree of plural sourcing complexity with a dditional challenges, such as measuring end-to-end services, aligning contracts across providers, managing relationships and collaboration, and defining standardization and modularization [21]. The traditional conclusion that firms will prefer to integrate complementary components now faces service governance challenges as GBS functions are provide $d$ by both in-house and outsourced vendors.

\subsection{Service governance}

Literature on governance shows that some studies focus on the importance of contractual governance a greements to manage outsourcing arrangements [6]. Specifying long-term contracts is complex and inherently incomplete becau se firm s have to deal with uncertainty and unanticipated obligations. Hence, firms should govern an outsourcing a rrangement beyond traditional contractual a greements and a lso con sider relationships [22]. Literature suggests that contrac tual governance and rela tional governance influ ence e ach other and can be perceived as complementary [6]. More specifically, service governance corresponds to the responsibilities within a firm to manage bu siness services. We build on the definition of [10] and define 
service governance as "a firm's overarching ca pacity and responsibility to direct, monitor and manage bu siness service operations".

Global business services within the context of plural sourcing differ in their a pproach compared to firm s tra ditional shared services (see Figure 1). Due to the characteristics of GBS, the degree of complexity to govern business services increases. Consequently, a firm has delegated resources, processes, and managerial control to independent ext ernal vendors. Wirtz et al. [5] argue that firms have to apply a centralized approach when governing their business services in order to integrate in to corporate strategies. Importantly, due to plural sourcing, the supply chain s of technology-intensive business services become more fragmented. This creates a new source of complexity because GBS are introduced in the contex t of plu ral sourcing that may require other service governance approaches.

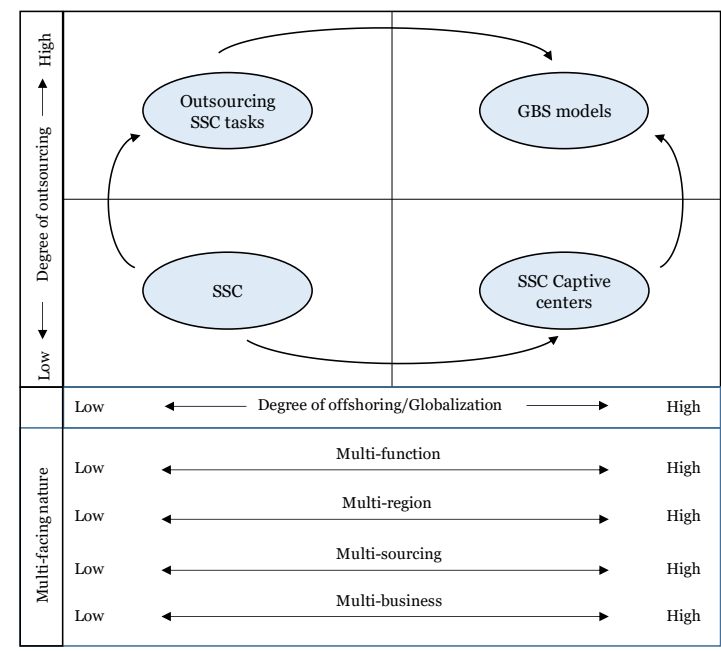

Figure 1. Evolution of GBS (adapted from Wirtz et. al, 2015)

\section{Research methodology}

We used Grounded Theory (GT) as a qualitative interpretative framework that is used in business [1 11 . Grounded theory is a n appropriate meth odology for this study for two reasons. First, GT is specifically used for theory generation and is oriented towards actions [23]. Due to the multi-faceted nature of GBS it can be argued that exploratory research is a relev ant method [24]. Second, GT allows us to consider many va riables at the same time. Previous studies in the field of GBS have used methods where few variables were introduced such as economics [5], technology [25], and business processes [26]. As we had a general idea of where to begin, we opted for the Straussian ap proach
[27]. The researchers started by describing the situa tions that may occur when governing GBSs in a plural sourcing context, and secondly, they play ed a n active role during the interviews, and structured the data to reveal the theory.

Our exploratory study design consists of two stages face-to-face interviews supported by an online questionnaire; and minicases to createin sight in the conceptualization of service governance modes. These approaches helped to identify and measure the service governance dimensions (degree of centralization, degree of functionality) and collecting complementary data for cross-validation and quantification of specific aspects of service governance. All variables were measured using 5-points Likert scales from valid ate d sources.

Regarding the first stage, data was gathered between January 2015 and February 2019, a nd base d on in-depthface-to-face interviews supported by a web questionnaire that was sent to the interviewees afterwards. As confidential and sensitive information is concerned, we anonymized the firms. A semistructured interview protocol was designe d to ga th er data. Interviews varied from 60 minutes to 120 minutes in duration. Theinterviewees that participated in the interviews and questionnaire held positions like CEO, CIO, CFO, Head of business services, (Senior) Vice President, and director. We distributed in total 267 invitations and the final sample contained 68 respondents, as such response rate was $25 \%$. As the data was collected on a global level, th is rich dataset is quite unique, representing a population of interna tionally operating firm s in diverse industries.

Addressing the second stage, we drafted five (5) mini cases to operationalize the identified service governance modes. We used closed, prompted and precoded questions to collect data. As coding is the key process in grounded theory [23], we transcribed the 68 interviews and thoroughly and manually coded the data by focusing on main ideas in paragraphs (open coding). As a next step, the codes were grouped into categories (axial coding), which correspond to [28] suggested coding paradigm. Consequently, we divided the categories into subcategories and grou ped the codes accordingly. Each category and subcategory were developed in a memo, and memos were sorted to create the theory a round the core categories [28].

\section{Findings \\ 4.1. Context}

The descriptive analysis of the 68 respondents show that the firms operate across ten different industries. Firm s in Energy \& Utilities, Manufacturing, Financial Services, and Pharma are overre pre sen ted, 
whereas, Food and Beverage is the least represen ted firms, as shown in Table 1. To indicate the de gree of outsourcing of the firms under study, we followed [29] differentiation in three levels of outsourcing. A low degree of outsourcing denotes a budget of less than $20 \%$, a medium degree of outsourcing exists of sh are s between $20 \%$ and $50 \%$, while a high degree of outsourcing means that more than $50 \%$ of the a nn ual budget is used for outsourcing. The descriptive analysis shows that the majority of the firm s: F\&A (N $=34), \mathrm{HR}(\mathrm{N}=48)$ as well as Procurement and SCM $(\mathrm{N}=54)$ have a low degree of outsourcing. However, with respect to IT, we observe that a s much as 32 fims have more than $50 \%$ of their IT outsourced, see Table 2 for more information. We also measured the size of firms (small firms $=\langle 10.000$ fte and large firms $\rangle$ $10.000 \mathrm{fte}), 33(49 \%)$ were small firm and the rest $(\mathrm{N}=$ 35 ) were large firms. The business services under study are supported by Enterprise Information sy stems and range from 1 up to 10 systems per firm (e.g., SAP, Oracle, JD Edwards).

Table 1. Distribution of Firms within their Industries

\begin{tabular}{lcc}
\hline Industry & Firms & \% \\
\hline Consumer Products & 4 & $6 \%$ \\
Diversified Conglomerate & 5 & $7 \%$ \\
Energy \& Utilities & 13 & $19 \%$ \\
Financial Services & 8 & $12 \%$ \\
Food \& Beverages & 2 & $3 \%$ \\
Logistics & 4 & $6 \%$ \\
Manufacturing & 7 & $0 \%$ \\
\hline
\end{tabular}

\begin{tabular}{lcc}
\hline Pharma & 13 & $19 \%$ \\
Professional Services & 4 & $6 \%$ \\
Public Sector & 4 & $6 \%$ \\
Other & 4 & $6 \%$ \\
Total & 68 & $100 \%$ \\
\hline
\end{tabular}

To explore how the firms under study deal with service governance, we observed five service governance modes in which GBS are governed. These modes refer to: a) decentralized, b) centralized, c) regional, d) global and e) multifunctional. When addressing a decentralized approach, each organizational department per country govern business services on their own behalf. By using a centralized approach, business services are consolidated and owned by a centralized function (i.e., org a nizational entity per country). Next, when applying a regional approach, business services are consolidated in a regiona lorganizational entity (i.e., Europe). B u sines s services that are implemented at a global level are governed by a global orga nizational entity, which is accountable for business service delivery and performance. Finally, when a pplying a multifunctional approach, various business services, for instance F\& A and $\mathrm{HR}$, are governed from an integrated perspective, applying an end-to-end process ownership and accountability. Based on the findings, we identified the relationship between the service governance modes and the degree of outsourcing (Table 3 ).

Table 2. The Degree of Outsourcing

\begin{tabular}{|c|c|c|c|c|c|c|c|c|}
\hline \multirow[t]{2}{*}{ Degree of outsourcing } & \multicolumn{2}{|c|}{$\mathbf{F \& A}$} & \multicolumn{2}{|c|}{ IT } & \multicolumn{2}{|c|}{ HR } & \multicolumn{2}{|c|}{ Procurement/SCM } \\
\hline & Firms & $\%$ & Firms & $\%$ & Firms & $\%$ & Firms & $\%$ \\
\hline Low $(<20 \%)$ & 34 & $50 \%$ & 28 & $41 \%$ & 48 & $71 \%$ & 54 & $79 \%$ \\
\hline Medium (20\%-50\%) & 18 & $26 \%$ & 8 & $12 \%$ & 12 & $18 \%$ & 8 & $12 \%$ \\
\hline High $(>50 \%)$ & 16 & $24 \%$ & 32 & $47 \%$ & 8 & $12 \%$ & 6 & $9 \%$ \\
\hline Total & 68 & $100 \%$ & 68 & $100 \%$ & 68 & $100 \%$ & 68 & $100 \%$ \\
\hline
\end{tabular}

Table 3. Service Governance and Degree of Outsourcing

\begin{tabular}{|c|c|c|c|c|c|}
\hline & & F\&A & IT & HR & Procurement/SCM \\
\hline Service governance mode & Degree of outsourcing & Firms & Firms & Firms & Firms \\
\hline \multirow[t]{3}{*}{ Decentralized (4 firms) } & Low $(<20 \%)$ & 2 & 2 & 4 & 4 \\
\hline & Medium $(20 \%-50 \%)$ & 0 & 1 & 0 & 0 \\
\hline & High $(>50 \%)$ & 2 & 1 & 0 & 0 \\
\hline \multirow[t]{3}{*}{ Centralized (30 firms) } & Low $(<20 \%)$ & 20 & 8 & 24 & 26 \\
\hline & Medium $(20 \%-50 \%)$ & 9 & 3 & 4 & 4 \\
\hline & High $(>50 \%)$ & 1 & 19 & 2 & 0 \\
\hline \multirow[t]{3}{*}{ Regional (14 firms) } & Low $(<20 \%)$ & 6 & 7 & 8 & 11 \\
\hline & Medium $(20 \%-50 \%)$ & 3 & 2 & 3 & 1 \\
\hline & High $(>50 \%)$ & 5 & 5 & 3 & 2 \\
\hline
\end{tabular}




\begin{tabular}{llcccc}
\hline Global (15 firms) & Low (<20\%) & 5 & 10 & 9 & 11 \\
& Medium (20\%-50\%) & 3 & 2 & 3 & 2 \\
& High (>50\%) & 7 & 3 & & \\
& & & & & \\
\hline & Low (<20\%) & 1 & 1 & 3 & 3 \\
\hline Multifunctional (5 firms) & Medium (20\%-50\%) & 3 & 0 & 2 & 0 \\
& High (>50\%) & 1 & 4 & 0 & 2 \\
\hline
\end{tabular}

Table 4. Rationales

\begin{tabular}{|c|c|c|c|c|c|}
\hline \multicolumn{6}{|c|}{ Service governance modes } \\
\hline Rationale & Decentralized & Centralized & Regional & Global & Multifunctional \\
\hline Drive growth \& realize synergies from acquisitions & 1.75 & 3.15 & 3.93 & 2.87 & 2.60 \\
\hline Drive growth in emerging markets & 1.50 & 1.78 & 2.93 & 2.50 & 2.60 \\
\hline $\begin{array}{l}\text { Align the operating model to mitigate overall business } \\
\text { risk and ensure compliance }\end{array}$ & 4.50 & 4.28 & 4.57 & 4.00 & 3.80 \\
\hline $\begin{array}{l}\text { Optimize the global operations footprint and ability to } \\
\text { scale }\end{array}$ & 3.75 & 3.38 & 3.86 & 3.60 & 4.60 \\
\hline $\begin{array}{l}\text { Unlock the power of data \& analytics to drive greater } \\
\text { insight }\end{array}$ & 3.50 & 3.54 & 3.71 & 3.27 & 2.80 \\
\hline Establish consistent customer and brand experience & 3.50 & 2.96 & 3.50 & 2.86 & 3.00 \\
\hline Drive process excellence and collaboration & 4.00 & 4.44 & 4.00 & 4.58 & 4.50 \\
\hline Build internal repository of high-quality talent & 1.25 & 3.39 & 2.80 & 3.80 & 3.00 \\
\hline Total number of firms & $\mathrm{N}=4$ & $\mathrm{~N}=30$ & $\mathrm{~N}=14$ & $\mathrm{~N}=15$ & $\mathrm{~N}=5$ \\
\hline
\end{tabular}

Note: we asked respondents to indicate their perception of the identified rationales with 1 "less important" to 5 "most important".

To create a better understanding of why firms implemented a specific mode of service governance, we identified various type of rationales (see Table 4). The findings illustrate that the rationales "a lignment of a firm 's operating model to mitiga te business risks and ensure compliance" and "drive process excellence a nd collaboration" are perceived as im portant a cross all service governance modes. On the other hand, we fin d distinctions between service governance modes, such as "drive growth in emerging markets" and "build internal repository of high-quality talent" that are perceived as less im portant for the decentralized form of service governance.

\subsection{Mini cases}

The identified service governance modes can be seen as strategic instruments, which are dependent on the implementation of a firm's GBS. As these service governance modes vary, we describe the fivecommon modes in more detail by means of mini cases to opera tionalize their concept. In doing so, we provide an in-depth view in how GBS are governed within a plural sourcing context. The mini cases all represent internationally operating firms that are part of the resea rch design $(\mathrm{N}=68)$.

\subsubsection{Mini Case Decentralized Service Governance Mode}

The minicase under study provides services in the field of hospitality and real estate services in more than 50 countries. We studied firm's decentralized situation in Denmark specifically. The motivation to implement GBS is twofold. First, the firm's business strategy is to establish a consistent customer and brand experience. Second, originally, the customer experience driven strategy required processes that were customized to some degree. Currently, the firm aims to st andardize these processes to cater for changing cust omer nee ds (drive process excellence). To respond to changing client need a dequately, customized business services are provided. This decision corresponds to the firm's strategy to develop a service brand ex perience in ea ch country. More recently in 2018 , the firm experienced that services lead times increased due to the high degree of customization. To improve le a d tim es, the firm started an optimization initiative. As such, business processes are analyzed from the view of standardization with the goal to improve process excellence while remaining the focus on customer needs.

During the implementation of business services in 2014, the firm developed a plural sourcing strategy. Due to the focus on decentralization, we found that F\&A, HR, and SCM services are predominantly provided in-house (low degree of outsourcing: $<20 \%$ ). An exception is found with regard to IT services which 
are partially outsourced specifically in the field of IT infra structure services (medium degree of outsourcing: $20 \%-50 \%$ ). Based on the plural sourcing stra te gy the responsible business executive argued that:

"over the lastfew years, we built a true business platform. This allows us to offer consistent and integrated facility service solutions to our cu stomers. One common IT vendor will further help us strengthen our offer to customers with operations in the region".

\subsubsection{Mini-Case Centralized Service Governance Mode}

The mini case that reflects a centralized service governance mode represents a consulting firm. The firm provides consulting services in the field of financial services and digital strategies in more than 100 countries. We studied business services in the Netherlands. The firm's main ra tionale to implement a centralized approach in 2016 was to improve the degree of effectiveness of their operating model to mitigate business risks (increase of consulting lead times). Before organizing business services on a centralized level, the firm did not pay sufficient attention to manage existing business processes. As a consequence, the lead time to provide essential fina ncial and HR information to employees in creased and resulted in internal debates about quality and professionalism. The firm decided to optimize existing business processes to improve the quality. The firm 's Chief Operating Officer (COO) in the Netherlands stated:

"we do have to improveand strengthen existing internal business services and processes first to safe guardour consulting services to clients. Repairing and optimizing our business processesis es sential to streamline business activities and increase client satisfaction".

The firm redesigned their orga nizational st ruct ure and madea split between a Business Service Center department (standardized services) and a Center of Excellence department (customized services). The head of business services, which is responsible for both the BSC and CoE, argued that:

"the split between standardized and customized type of tasks support our centralized business processes. By using this approach each business service is able to maximize the sup port tow ards our employees and improve the quality and ease of use".

Considering the firm's plural sourcing approach, ourfindings show thatF\&A, HR, and Procurements services are provided in-house (low degree of outsourcing: <20\%). In contrast, the vast maj ority of IT services are provided by external vendors (high degree of outsourcing: $>50 \%$ ).

\subsubsection{Mini-case Regional Service Governance mode}

The mini case under study is a European manufacturing firm providing products in the fie ld of consumer goods. Business services are provided by means of a regional (ca ptive) delivery center located in Poland. The main rationale to initiate a regional approach is driven by costreductions and the need to become a more agile organization. The firm established a dedicated organizational unit in 2016 , labeled a s the business services organization (BSO) to govern all internal business services. We find that standardizing business processes is perceived as a barrier as commercial bu siness units and the BSO have to a lign business process tasks. The firm's decision to regiona lly govern all business services resulted in the harmonization of existing business processes. One of the interviewees put forward that:

"where to start, that is the question? So, we decided to transform by means of 'waves' in which we transform our business services each at the time. We started to redesign $F \& A$ services first as we have a long history and experience based on our captive services".

The BSO is staffed with over 1,000 dedicated employees and is responsible to develop and main tain a plural sourcing strategy, corresponding policies and processes, and contract and manage external vend ors. Our analysis shows that from a plural sourcing perspective $\mathrm{F} \& \mathrm{~A}$ business services are outsourced to external vendors (high degree of outsourcing: > 50\%), while IT, HR, and Procurement/SCM services are provided in-house (low degree of outsourcing: $<20 \%$ ).

\subsubsection{Mini-Case GlobalService Governance Mode}

Addressing a global service governance mode, we studied a firm operating in the consumer market specialized in beverages production. In the 90 's, the firm initiated the implementation of captive shared service centers and importantly, in 2016 the firm merged with a market competitor. The motivation to implement a global service governance mode was based on two drivers: achieve growth based on synergies from the merger and acquisition and the design of a single operating model. The firm under study established a new organizational entity (global business services unit) thatexists of three la yers. First, a global capability center in India was set up that 
focuses on off-shore, language-independent services to support day-to-day business processes. Second, five regionalca pability centers (Czech Republic, Mexico, Brazil, South Africa, Malaysia) were implemented to execute business services. Third, country capability centers are introduced to execute busin ess processes that are still in an incubation phase and ca nnot be transferred to a regional of the global capability center. An executive manager stated that:

"we decided to create a clear demarcation between strategic (client) andoperational activities (external vendors) in supporting business services. This approach contributes to a strict focus on applying standardization. From a governance view, it becomes clear who is responsible for what type of activities".

Due to the merger and acquisition between both firms the need arose to harmonize business process es. At stra tegic level, the decision was made to implement a top-down strategy and harmonize business processes by means of information systems. From a plural sourcing perspective, we found that F\&A and IT business services as delivered by the regional ca pability centers, a re outsourced to external ven dors (high degree of outsourcing: > 50\%). HR and procurement services on the other hand are mainly provided in-house (low degree of outsourcing: $<20 \%$ ).

\subsubsection{Mini case Multifunctional Service Governance mode}

When studying the multifunctional governance mode, we noticed that the firm understudy provides machineequipment components in the field of civil en gineering. The firm faces fierce market competition and initiated a cost reduction program to reduce overhead. Hence, their drivers to implement the multifunctionalmode rela te to improve their bu sines $s$ processes (process excellence) as well as align their operating model. From a norganization view, a global centra lized teamwa s responsible for business service s strategy tasks while each country was responsible for the operationalization of business services. To achie ve cost reduction goals the firm decided to chan ge their organization into a fullcentralized model. At a glob a 1 level the firm started to bundle business services and manage them as a whole since various services are interrelated (e.g., HR and IT, F\&A and IT, Procurement and Legal). Next, the firm identified F\&A, HR, and Procurement as outsourcing candidates (> 50\% degree of outsourcing) that con tribute to the cost reduction goals. A senior directed mentioned:

"up till now we provided all business services inhouse by means of our captive centers in India which offered interesting costreductions in the past. As we have to decrease our cost level again, we intent to outsource various services to multiple glob al service providers".

From a plural sourcing view, the interviews showed that by outsourcing business services external vendors will automate routine-oriented business services tasks by means of robotics, machine learning, and cognitive solutions. In doing so, the vendors a re able to reduce the cost level by $30 \%$. The multifunctional a pproach, however, increases the degree of governance as interrela ted bu siness services are partially provided inhouse and partially outsourced.

\section{Discussion}

We discuss our findings on the basis of four sections (e.g., rationales, organizational structure, service governance modes and plural sourcing), which allowed us to answer our research question "whattype of service governance modes are used by firms to implement globalbusiness services when applying a plural sourcing strategy?”

\subsection{Firms' rationale}

Analyzing firms' rationale to implement global business services, our findings show that process excellence and alignment offirms' operating models are indicated a key drivers. Irrespectively of the type of service governance mode, both rationales are considered to be the key drivers of firms' objective to implement global business services. The key driver process excellence corresponds to a firm's need to decrease their cost level which is consistent with previous findings. Literature shows that firm s' original motivation to establish shared service centers were mainly based on achieving cost reductions as confirmed through many case studies [30-32]. This finding is supported by a litera ture study of [6], who argue that achieving cost reductions is perceived to be a main motivation that drive sourcing decisions. Importantly, our analysis on firms' rationale to a lign their operating model can be perceived as a novel finding. Our interviews provide evidence that firms develop a coherent view to align the delivery of internal and external (outsourced) busine ss services, business processes, technology, knowledge and skills. In doing so, firms' a im is to a chieve a balance between various determinants in which they are complementary when implementing global bu siness services. We a rgue that alignment of a firm's operating model forms a key prerequisite to implement global business services and contribute to a successful plural sourcing strategy. In 
doing so, firms become more adaptive to cater for changing needs.

\subsection{Organizational structure}

When studying the mini cases our findings show that each firm, with the exception of the decentralized mode, established an organizationalentity to govern globalbusiness services. We found that this entity is responsible for various tasks including developing policies, managing internal and external service providers, harmonizing business processes, and sharing knowledge. Hence, these determinants can be perceived as a firm's dynamic capability. Teece et a l. [33] argued that organizations require dynamic resources to manage and orga nize both content and processes to achieve sustainability.

This dynamic capability is needed to implement and sustain global business services within a plural sourcing context. Moreover, the organizational entity can be perceived as a bridging role (boundary spanner) between internal customers and internal a nd external vendors. Our analysis indicates that developing policies and guidelines and exchanging knowled ge to manage the plural sourcing environment supported the implementation of globalbusiness services. Em ployees as a part of a norganizational entity are responsible to communicate agreements, such as policies and performance towards internal customers as well as external vendors. Literature indicates that $\mathrm{kn}$ owle dge transfer is an important aspect of exchanging information between geographically dispersed tea ms [34]. Therefore, we would argue that boundary spanners should be an essential part of knowled ge transfer within a plural sourcing environment and, a s such, they can help improve communication and trust between actors.

\subsection{Service governance modes}

While studying the various service governance modes, we found that the vast majority of firm sopt to apply a central mode ( 30 firms out of 68) to govern their business services. This finding is consistent with [5] that firms have to apply a centralized approach when governing their business services in order to integra te them with corporate strategies. Interestingly, our study indicates that both a regional mode (14 firms) and a global mode ( 15 firms) are perceive d a s alternatives for the central mode. Our findings on the firms' key ra tionales (i.e., a lign firms operating model and process excellence) corresponds to the objective of international operating firms to decrease the level of complexity. This may explain why a certain degree of centralized type of service governance mode (i.e., central, regional, global) is implemented as a favorable option. Importantly, we find two exceptions. First, four firm s choose to govern their business service s from a decentralized perspective, while five firms decided to apply a multifunctional governance mode. An expla nation may be found in a lack of standardization of business services and supporting business processes, which increa ses governance complexity. According to [26] the choreography of services is essential to cre ate business process flexibility and, as such, modularized business services that can be managed in various configurations, are a precondition to support bu siness services. We argue that firms which have modularized business processes can implement global business services more effectively.

\subsection{Plural sourcing context}

In general, we found that firms vary in their decision to deliver business services in-house or outsource services to the market. Our a nalysis indicates that firms who apply a centralized service governance mode decided to keep their F\&A services predominantly in-house (low degree of outsou rcing). Interestingly, the more F\&A services are governed from an international perspective (i.e., regional, global), the more the degree of $F \& A$ outsourcing increases. This may be explained by the historical experience of firms that established captive centers in order to benefit from labor arbitrage, while standardizing services at the same time [35]. Moreover, our study reveals that IT services, which are governed from a centralized perspective, are predominantly outsourced to the market (19 out of 30 firms). Remarkably, the degree of IT outsourcing varies with regard to the other service governance modes. We expected to find that firms outsource IT services to a large extent as the IT service provider market is perceived as mature since its growth in the 90s [6].

In contrast, $\mathrm{HR}$ and Procurement/SCM findings indicate that for the vast majority of service governance modes the degree of outsourcing is low. Cooke et al. [36] argue that a loss of in-house knowledge and capacity as well a s quality re duction s in HR work ca use firm s to be hesitant in ou t sou rcing these ta sks to the market. This maybe an ex pla nation why firms are reluctant to outsource HR tasks. Addressing Procurement/SCM services, ou r findings also illustrate a low degree of outsourcing $(<20 \%)$, which is contrasting with research of [37]. The a uthors found that decentralized decision-making will result in a higher degree of outsourcing SCM functions. 


\section{Conclusions}

The aim of our research is to explore how firms deal with service governance of global business services (GBS) within the context of plural sourcing. In doing so, we respond to the call of [11] for more explorativeresearch from a buyer pers pective in the context of service sourcing and service outsourcing. Our findings operationalize and extend the view of [5] addressing a new wave of global business services, which a re applied a cross borders, that have emerged as drivers of growth in the world's service sector. B ased on a rich and unique dataset that represents 68 interna tional operating firm s in va rious ind ustries, ou r study contributes to service-oriented [5], [11], [12] and sourcing literature [6], [17] in a number of ways. First, by studying firms' rationale to implement global business services, the variance of key drivers was made more explicit. The main rationales are driven by process excellence and the need to align firms' opera ting model. Irrespectively of the type of service governance mode, both ra tionales are considered to be the key drivers. When achieving these rationales, firms' degree of effectiveness in delivering business service will increase. In particular, our insights on firms' rationale to align their operating model go beyond the findings of [38] as research on motives show thateconomic motives are the most common, followed by strategy and service quality.

Second, by identifying five different service governance modes, we theoretically contribute to service governance, global business services and plural sourcing research. Research reveal that shared serv ice centers use both market and bureaucratic practices [39]. We extended these findings and illu stra ted that service governanceis a prerequisite to create a cle ar demarcation between in-house or outsourced business service tasks and as such, contribute to enterprise ecosystem flexibility. Third, firm s differ in the de gree to which they outsource business services. In particular, F\&A and IT services are outsourced to a medium and high degree. In contrast, HR and Procurement/SCM services predominantly correspond to a low degree of outsourcing.

This research has implications for practitioners and particularly for executive management of business services orga nizations. Our results suggest that firms require a certain degree of maturity to implement business services within the context of a plural sourcing stra tegy. Thus, we argue that organizations leadership have to create a fit between the level of management maturity, the selected service governance mode, and degree to which business services are outsourced. Based on that fit firms are able to improve the value of implementing a global business service arrangement. This research is not without limitations. Even though we attempted to objectify interpretation s of the interviews when coding, subjective bia s might not have been entirely eliminated, thus, the validity of the results could be influenced by the authors' in itia 1 point of view in terms of conducting, coding and interpreting the interview.

\section{References}

[1] Deloitte GBS. (2018). Future of Global Business Services: Catalyst for Enterprise Digital Transformation. https://www2.deloitte.com/us/en/pages/operations/articles/gl obal-business-services-digital-transformation.html.

[2] KPMG Insights. Global Business Services at a Crossroads: Results from the KPMG/HFS Research State of Operations Survey. Retrieved 15.11.2020 (2019).

[3] Janssen, W.F.W.A.H., Joha, A., and Weerakkody, V. (2007) Exploring Relationships of Shared Service Arrangements in Local Government. Transforming Government: People, Process \& Policies 1, 3 (2007), pp. 271-284.

[4] Niehaves, B. and Krause, A. Shared Service Strategies in Local Government: A Multiple Case Study Exploration. Transforming Government: People, Process \& Policies , 4, 3 (2010), pp. 266-279.

[5] Wirtz, J., Tuzovic, S. and Ehret, M. Global Business Services: Increasing Specialization and Integration of the World Economy as Drivers of Economic Growth. Journal of Service Management 26, 4 (2015), pp. 565-587.

[6] Lacity, M. C., Khan, S. A. and Yan, A. Review of the Empirical Business Services Sourcing Literature: An Upd ate and Future Directions. In Outsourcing and Offshoring Business Services (pp. 499-651).(2017) Palgrave Macmillan, Cham.

[7] Puranam, P., Gulati, R., Bhattacharya, S. How Much to Make and How Much to Buy? An Analysis of Optimal Plural Sourcing Strategies. Strategic Management Journal 34, 10 (2013), pp. 1145-1161.

[8] Rai, A., Keil, M., Hornyak, R. and Wüllenweber, K. Hybrid Relational-Contractual Governance for Business Process Outsourcing. Journal of Management Information Systems 29, 2 (2012), pp. 213-256.

[9] Heide, J.D. Plural Governance in Industrial Purchasing. Journal of Marketing 67 (2003), pp. 18-29.

[10] Aier, S., Bucher, T. and Winter, R. Critical Success Factors of Service Orientation in Information Systems Engineering. Business \& Information Systems Engineering 3, 2 (2011), pp. 77-88.

[11] Holmlund, M., Kowalkowski, C. and Biggemann, S. Organizational Behaviour in Innovation, Marketing, and Purchasing in Business Service Contexts: An Agenda for Academic Inquiry. Journal of Business Research 69, 7 (2016), pp. 2457-2462.

[12] Huber, B. and Danino, S. Global Business Services: Taking Business Support Functions to the Next Level. Information Services Group, Stamford, CT. (2012).

[13] Maatman, M., Bondarouk, T. and Looise, J. K. Conceptualizing the Capabilities and Value Creation of HRM Shared Service Models. Human Research management Review 20, 4 (2010), pp. 327-339. 
[14] McIvor, R., McCracken, R. and McHugh, M. Creating Outsourced Shared Services Arrangements: Lessons from the Public Sector. European Management Journal 29 (2011), pp. 448-461.

[15] Rao, M. T., Earls, T. W., and Sanchez, G. Internation al Collaboration in Trans-organizational Systems Development: The Challenges of Global Insourcing. Journal of Global Information Technology Management 10, 3 (2007), pp. 52 69.

[16] Heide, J.B., Kumar, A. and Wathne, K.H. Concurrent Sourcing, Governance Mechanisms, and Performance Outcomes in Industrial Value Chains. Strategic Managemen t Journal 35 (2014), pp. 1164-1185.

[17] Tiwana, A and Kim, S.K. Concurrent IT Sourcing: Mechanisms and Contingent Advantages. Journal of Management Information Systems 33, 1 (2016), pp. 101-138. [18] Krzeminska, A., Hoetker, G. and Mellewigt, T. Reconceptualizing Plural Sourcing. Strategic Management Journal 34, 13 (2013), pp. 1614-1627.

[19] Bradach, J.L. Using the Plural Governance Form in the Management of Restaurant Chains. Administrative Science Quarterly 42, 2 (1997), pp. 276.

[20] Wahrenburg, M., Hackethal, A., Friedrich, L. and Gellrich, T. Strategic Decisions Regarding the Vertical Integration of Human Resource Organizations: Evidence for an Integrated HR Model for the Financial Services and Nonfinancial Services Industry in Germany, Austria and Switzerland. The International Journal of Human Resource Management 17, 10 (2006), pp. 1726-1771.

[21] Plugge, A.G., Joha, A., Janssen, W.F.W.A.H. Coordinating Tensions in Orchestrating Blended Modes of Sharing and Outsourcing of Services. In I. Oshri, J. Kotlarsky, and L.P. Willcocks (Eds.): Global Sourcing 2013 LNBIP 163, pp 147-162, 2013 Springer-Verlag Berlin Heidelberg 2013.

[22] Lioliou, E., Zimmermann, A., Willcocks, L.P. and Gao, L. Formal and Relational Governance in IT Outsourcing: Substitution, Complementarity and the Role of the Psychological Contract. Information Systems Journal 24, 6 (2014), pp. 503-535.

[23] Strauss, A. and Corbin, J. Basics of Qualitative Research: Grounded Theory Procedures and Techniques. London, UK: SAGE Publication. (1990).

[24] Miles, M. and Huberman A. Qualitative Data Analy s is . Sage California (1994).

[25] Fremantle. P., Weerawarana, S. and Khalaf, R. Enterprise Services: Examining the Emerging Files of Web Services and How it is Integrated into Existing Enterprise Infrastructures. Communications of the ACM 45, 10 (2002), pp. 77-82.

[26] Van der Aalst, W.M.P. A Decade of Business Process Management Conferences: Personal Reflections on a Developing Discipline, In A. Barros, A. Gal, and E. Kindler (Eds.): Business Process Management, LNCS 7481, Springer-Verlag Berlin Heidelberg. (2012).

[27] Hekkala, R. Grounded Theory - The Two Faces of the Methodology and Their Manifestation in IS Research. Proceedings of the 30th Information Systems Research Seminar in Scandinavia IRIS, 11-14 August, Tampere, Finland (2007).
[28] Glaser, B.G. and Strauss, A.L. The Discovery of Grounded Theory: Strategies for Qualitative Research. Aldine, Chicago (1967).

[29] Dahlberg, T and Lahdelma, P. IT Governance Maturity and IT Outsourcing Degree: An Exploratory Study. In: Proceedings of the 39th annual Hawaii International Conference on System Sciences, (2007), paper 236a.

[30] Janssen, M. and Joha, A. Motives for Establishing Shared Service Centers in Public Administrations, International Journal of Information Management 26, 2 (2006b), pp. 102-115.

[31] Borman, M. Characteristics of a Successful Shared Services Centre in the Australian Public Sector, Transforming Government: People, Process and Policy 4, 3 (2010), pp. 220-231.

[32] Ulbrich, F. Adopting Shared Services in a Public-Sector Organization. Transforming Government: People, Process and Policy 4, 3 (2010a), pp. 249-265.

[33] Teece, D. J., Pisano, G. and Shuen, A. Dynamic Capabilities and Strategic Management. Strategic Management Journal 18, 7 (1997), pp. 509-533.

[34] Jin, X., Kotlarsky, J. and Oshri, I. Towards Understanding Knowledge Integration in Multi-Sourcing Engagements. In R. Hirschheim, A. Heinzl, and J. Dibbern (Eds.), Information Systems Outsourcing: Towards Sustainable Business Value (2014), pp. 273-287. Springer Berlin Heidelberg, Berlin, Heidelberg.

[35] Oshri, I. Offshoring strategies: Evolving captive center models. MITT Press, Cambridge, Massachusetts, London, England. (2011).

[36] Cooke, F.L., Shen, J. and McBride, A. Outsourcing HR as a Competitive Strategy? A Literature Review and Assessment of Implications. Human Resource Manage men t 44, 4 (2005), pp. 413-32.

[37] Davis-Sramek, B., Fugate, B. S., Miller, K., Germin, R., Izyumove, A. and Krotiv, K. Understanding the Present by Examining the Past: Imprinting Effects on Supply Chain Outsourcing in a Transition Economy. Journal of Supply Chain Management 53, 1 (2016), pp. 65-86.

[38] Richter, P.C. and Bruhl, R. (2017) Shared service center research: A review of the past, present, and future. European Management Journal 35, 3 (2017), pp. 26-38.

[39] Herbert, I. P. and Seal, W. B. Shared services as a new organizational form: Some implications for management accounting. The British Accounting Review 44, 2 (2012), pp. 83-97. 